\title{
Effects of Interventions Addressing School Environments or Educational Assets on Adolescent Sexual Health: Systematic Review and Meta-analysis
}

\begin{abstract}
CONTEXT: School-based interventions that aim to modify sexual health knowledge, attitudes and behaviors have mixed and often unsustained effects on adolescent sexual health outcomes. However, observational evidence suggests that broader school-related factors, such as school climate and academic attainment, can influence outcomes.

METHODS: Nine databases were searched in July 2017 for randomized and quasi-experimental evaluations of interventions addressing school-level environment or student-level educational assets, to examine whether such interventions can promote young people's sexual health. Searches were limited to studies published since 1990 but were not restricted by language. Studies were assessed for risk of bias and synthesized narratively and meta-analytically.
\end{abstract}

RESULTS: Searches yielded 11 evaluations, published from 1999 to 2016, of interventions related to school-level environment or student-level educational assets. Because of inconsistent reporting, the risk of bias was not clear for most studies, and meta-analysis was possible for only one outcome. The meta-analysis of three randomized trials provided some evidence that school-environment interventions may delay sexual debut (pooled odds ratio, 0.5). Narrative synthesis of the remaining outcomes found mixed results, but suggests that interventions addressing school-level environment may delay sexual debut and that those addressing student-level educational assets may reduce risk of pregnancy and STDs.

CONCLUSIONS: Additional and more rigorous evidence is needed to assess the probability that interventions addressing school-related factors are effective and to provide better understanding of the mechanisms by which they may work to improve adolescent sexual health.

Perspectives on Sexual and Reproductive Health, 2019, 51(2):TK, doi:10.1363/psrh.12102

Adolescent pregnancy and STDs remain public health concerns in the United States and internationally. Although rates of unintended pregnancy and unplanned birth are declining globally, ${ }^{1}$ they vary widely by geography and are disproportionately high among young people who are disadvantaged in terms of socioeconomic status, ethnicity and educational attainment. ${ }^{2-4}$ Moreover, young people aged 15-24 have the highest global rates of new diagnoses of curable STDs. ${ }^{5}$ The elevated rates of these outcomes in young populations are driven by disproportionate levels of sexual risk behaviors-including early sexual initiation, having multiple sex partners and lack of contraceptive or condom use-among socially disadvantaged youth. ${ }^{6-8}$ Government policy to address these behaviors globally has largely focused on classroom-based sex education; ${ }^{9}$ however, the effects of such education are inconsistent and often unsustained, ${ }^{10,11}$ suggesting that sex education is insufficient to produce long-term changes in sexual behavior, ${ }^{12}$ perhaps because it typically fails to address such social factors as educational disengagement and underattainment. ${ }^{13,14}$ Furthermore, curriculum-based sex education is becoming increasingly difficult to implement, given the demands on schools to meet academic targets, ${ }^{15,16}$ and may be particularly challenging to sustain in areas with conservative sex education policies. ${ }^{17}$ Thus, a role may exist for school-based interventions that aim to modify the school environment or promote educational attainment as "upstream" (i.e., distal) determinants of sexual health. ${ }^{18}$

Several theoretical models, such as the positive youth development framework ${ }^{19}$ and the social developmental model, ${ }^{20}$ have posited that schools play an important role in youths' sexual behavior. In particular, these models suggest that educational engagement, skill development, and attachments to prosocial individuals and institutions are associated with reductions in sexual risk behaviors However, these frameworks have not fully theorized the mechanisms by which school environments and educational assets might work to promote sexual health. ${ }^{21}$ The theory of human functioning and school organization ${ }^{22}$ is unique in proposing that institutional processes might facilitate student commitment to learning and to the school's community and values. These commitments are theorized to be protective of student health because they facilitate the development of the practical reasoning, social affiliations and autonomy necessary for students to choose healthier behaviors over riskier ones (Appendix Figure 1, Supporting Information). The institutional processes theorized to build student commitment involve ensuring that instruction, discipline and management center on student needs; enhancing relationships between school staff and
By Amy J. Peterson, Melissa Donze, Elizabeth Allen and Chris Bonell

Amy J. Peterson is program manager, ETR, Scotts Valley, $C A$, and a doctoral degree candidate, Department of Public Health, Environments and Society, London School of Hygiene and Tropical Medicine, London. Melissa

Donze is city research scientist, Division of Epidemiology, New York City Department of Health and Mental Hygiene, New York. Elizabeth Allen is professor, Department of Medical Statistics; and Chris Bonell is professor, Department of Public Health Sociology, and head, Department of Public Health, Environments and Society - both at the London School of Hygiene and Tropical Medicine.

Additional supporting information may be found in the online version of this article at the publisher's website. 
students; incorporating students' broader development into academic education; and aligning the values of schools with those of their local communities.

This theory has been empirically and explicitly assessed via observational studies with measures of substance use and violence, but not measures of sexual health outcomes. ${ }^{23-26}$ Observational studies from high-income countries indicate that youth who report having caring relationships with adults at school, ${ }^{27}$ feeling attachment to school, ${ }^{28-32}$ being involved with school, ${ }^{33-35}$ having positive attitudes toward school ${ }^{36,37}$ and having high educational expectations and aspirations ${ }^{29,30,35,38}$ also report reduced rates of sexual risk behaviors and outcomes, including early sexual initiation, unprotected sex, and pregnancy and birth. Moreover, multilevel studies suggest that higher rates of school-level student bonding, positive attitudes toward school and educational expectations are associated with lower rates of early sexual debut and recent sexual activity. ${ }^{32,38,39}$ Furthermore, other academic attainment outcomes appear to have important associations with sexual health outcomes globally. A review of longitudinal studies from high-income countries found evidence that academic ability and achievement reduce the risk of early sexual debut, pregnancy and birth, and increase the likelihood of contraceptive use. ${ }^{40}$ In addition, observational studies from low- and middle-income countries provide strong evidence that school enrollment is associated with reduced rates of subsequent sexual debut and pregnancy. ${ }^{41,42}$ Although such evidence points to the potential for interventions that address these factors to promote sexual health, observational studies cannot control for confounding characteristics, such as socioeconomic status and other family-related factors, and cannot tell us whether, and to what extent, school- and educationrelated interventions can modify students' sexual behavior and health. Evidence from rigorous evaluations is needed to determine whether such interventions are indeed effective at changing important school-related determinants and subsequent sexual health outcomes.

Systematic reviews from outside the field of sexual and reproductive health suggest that interventions can address these school-related factors and improve health outcomes. For example, a review of cash transfer programs in lowand middle-income countries found that these programs consistently improved access to education in the short term, especially when the cash transfer was conditional (i.e., enrollment or attendance was required). ${ }^{43}$ A Cochrane review of the impact on student well-being of interventions modifying the school ethos or environment reported benefits for several aspects of student health (physical activity, tobacco use, nutrition and bullying victimization), but not for sexual health. ${ }^{44}$ The review could not assess academic-related outcomes because relevant measures were not reported. The Cochrane review, along with several other reviews, did explore the effects on sexual health of school-based interventions addressing school-level environments or student-level educational assets. ${ }^{44-46}$ However, these reviews are now several years old and did not aim to explore intervention mechanisms.
In this article, we build on past reviews by providing an up-to-date synthesis of evidence from studies that evaluated the effects of interventions addressing schoollevel environments or student-level educational assets (or both) on sexual behavior and health. We explore the plausibility and probability that these interventions are promising sexual health interventions. By focusing on interventions that address aspects of school life that align with the theory of human functioning and school organization, the review also aims to examine the pertinence of this theory to adolescent sexual health outcomes. While we did not aim to examine the effects of these interventions on educational outcomes, we have included reported academic results to provide additional context in our narrative review.

\section{METHODS \\ Study Design}

This review followed a registered protocol (PROSPERO record number CRD42017072169) and PRISMA guidelines. ${ }^{47}$ Studies were included if they reported evaluations of outcomes from school-based interventions that targeted adolescents (aged 10-19) and that explicitly described activities that either changed aspects of the school-level environment or aimed to improve student-level educational assets. We defined school-level environment interventions as those meant to improve school climate or culture, increase safety, change policies, improve access and connection to caring adults, or provide opportunities for student engagement in the school or community. Interventions were classified as addressing educational assets if they were designed to increase or improve student-level academic goal-setting, attendance, attainment, interest in school and school work, relationships with teachers and staff, and engagement with school.

To ensure that interventions met the aims of the review, we amended the review's protocol at the start of fulltext screening to clarify that for studies to be included, school-level or student-level intervention activities could not focus solely on sexual health education or services, but needed to engage more broadly with school organization or student educational assets. Thus, studies were excluded if they reported on interventions designed specifically to improve knowledge, attitudes, skills or services related to sexual health. In addition, to be eligible for the review, studies had to employ a randomized trial or quasiexperimental design, in which control groups received usual treatment or a comparison intervention, and they must have reported at least one sexual health outcome, such as pregnancy, STDs or sexual behaviors associated with increased risk of pregnancy or STDs. There were no language restrictions in searches or screening. We limited the searches to studies published in or after 1990, to avoid spending time screening older references that were unlikely to yield pertinent studies and to ensure that the included studies would be most applicable to relevant current policy. 


\section{Data Collection}

The search, conducted in July 2017, involved nine bibliographic databases: BiblioMap, CINAHL Plus, ERIC, IBSS, OpenGrey, ProQuest Dissertations \& Theses, PsycINFO, Medline and Web of Science Core Collection. Our search strategy consisted of free-text and subject-heading searches (Appendix Figure 2, Supporting Information). The search terms linked three concepts: school and education (i.e., the population and setting); sexual behavior, pregnancy or parenthood (the outcome); and intervention studies (the study type). We also searched Google using these concepts, checked references of included studies, and contacted subject matter experts using a standard form. Citations were managed using EPPI-Reviewer 4.

For each identified reference, we screened the title, abstract and, when necessary, the full report. Two of the authors double-screened 50 titles and abstracts and 15 full reports to pilot-test the eligibility tool and ensure that agreement between screeners was more than 90\%; the remaining references were divided among the two screeners and screened individually. Citations identified from web searches, subject matter experts and reference checks were screened online and cross-referenced with database searches. As is customary, only references identified via web searches were imported into EPPI-Reviewer 4. A final check of all included studies was made by two of the authors.

Using an extraction tool, two of the authors extracted data from each article or report on the study location, intervention, study design, sample size at baseline, attrition by follow-up, participant characteristics, sampling methods and all sexual health outcomes reported. We pilot-tested the extraction tool and codes by inputting data from four studies and then comparing inputs; when discrepancies occurred, the guidelines for the codes were discussed and modified. A standard contact form was used to request information from primary authors when detail was insufficient. If relevant, multiple reports of the same study were extracted separately and coded into a single entry. Risk of bias was assessed for randomized trials using the Cochrane Handbook for Systematic Reviews of Interventions risk-ofbias tool, ${ }^{48}$ and for quasi-experimental studies using the adapted EPPI-Centre tool. ${ }^{49}$ Bias domains assessed were random generation of allocation sequence; allocation concealment; blinding of participants, personnel and outcome assessors; completeness of outcome data; selective outcome reporting; accounting for clustering; and other sources of bias. Two of the authors independently assessed studies and assigned ratings (low, high or unclear risk, or not applicable) to domains within each study. Scores were then reconciled in EPPI-Reviewer 4 by one author and checked by another author.

\section{Analysis}

Randomized trials and quasi-experimental studies were synthesized narratively and, when appropriate, meta-analytically. Narrative summaries are reported by intervention type (e.g., school-level environment vs. student-level educational assets) and then by outcome and follow-up time. Effect sizes were imported into a Microsoft Excel spreadsheet and converted to uniform effect sizes (e.g., odds ratios) where required. Meta-analysis was conducted via EPPI-Reviewer 4's meta-analysis function, using fixed-effects analysis. The meta-analysis was done by intervention type and outcome, and prioritized the most long-term follow-up reported. Heterogeneity is reported using $\mathrm{I}^{2}$ estimates. When insufficient data or heterogeneity precluded meta-analysis, narrative summaries of effects are reported.

\section{RESULTS \\ Overview of Included Studies}

The search yielded 28,810 unique references, of which 28,485 were excluded on the basis of title and abstract (Appendix Figure 3, Supporting Information). We were able to obtain full reports for all but five of the remaining 325 references, and found that 11 outcome evaluations presented in 17 study reports published between 1999 and 2016 met the eligibility criteria (Table 1). ${ }^{50-66}$ Five of the 11 studies were from high-income countries (Australia and United States), four from middle-income countries (South Africa and Kenya) and two from low-income countries (Malawi and Zimbabwe). Five studies met the inclusion criteria for school-level environment interventions, , $2,55,58-63,65^{-6}$ and six for student-level educational asset interventions. ${ }^{50,51,53,54,56,57,64,66}$ No study addressed both.

Nine studies used a randomized design with allocation at the level of school, ${ }^{52,54,55,57,62,63,65}$ region $^{50,51,53,56}$ or individual, ${ }^{64}$ while two used a quasi-experimental design that matched intervention and comparison schools nonrandomly. ${ }^{58-61,66}$ Insufficient detail prevented complete assessment for most domains of bias risk; as a result, we rated the risk of bias as "unclear" for at least one domain in each study (Table 2). Only two randomized trials reported information on the majority of relevant domains, ${ }^{50,51,62}$ and none reported on all. The only domain for which most studies reported sufficient information was clustering: All but two cluster-allocated studies properly accounted for clustering. ${ }^{50-52,54,55,57,59,62,63,65}$ The authors of one quasiexperimental study confirmed that they did not adjust for school-level clustering because the study included only two schools. ${ }^{66}$ For one randomized trial, ${ }^{53,56}$ it was not clear from the study reports whether effects were adjusted for household-level clustering, and the authors did not respond to inquiries.

\section{School-Level Environment Interventions}

Of the five school-level environment interventions, three employed teams of school staff and students to improve school policies or practices addressing school climate $e^{52,55,63,65}$ or to improve safety and prevent sexual violence. ${ }^{62}$ Two interventions provided teachers with knowledge and skills related to classroom management and interactive teaching ${ }^{58-61}$ or to strategies to support actions recommended by school teams. ${ }^{63}$ All interventions 
addressing school-level environment included other components, such as social development or sexual health education curricula.

Only one meta-analysis was possible for outcomes of school-environment studies. Three randomized trials ${ }^{52,62,63}$ reported intervention effects on sexual debut and were included in the meta-analysis. The first trial, the Gatehouse Project, involved 25 secondary schools in Australia and reported on sexual debut (i.e., whether students had ever had sexual intercourse) among three cross-sectional samples of eighth-grade students at two and four years after baseline. ${ }^{63}$ Positive Action, the second trial, assessed sexual debut (i.e., lifetime voluntary sexual activity with the opposite gender) at four years postbaseline among a sample of U.S. youth from 20 schools who had been fifth graders at baseline. ${ }^{52,65}$ The third trial, PREPARE, was the only school-level environment intervention evaluated in a low- or middle-income country (South Africa). ${ }^{62}$ Sexual debut outcomes (i.e., whether youth had ever had vaginal or anal sex) were reported at six and 12 months after baseline among students (average age, 14 years at baseline) from 42 schools. A pooled analysis that included effect sizes for the three trials at the most long-term follow-up found that students in the intervention arms were less likely than those in the control arms to report sexual debut (odds ratio, 0.5; 95\% confidence interval, 0.4-0.7). There was, however, substantial between-study statistical heterogeneity $\left(\mathrm{I}^{2}=76 \%\right)$. The three studies were heterogeneous by location, follow-up times and participant age at intervention. The pooled estimate remained statistically significant in sensitivity analyses that focused on the first follow-up $(0.6[0.4-0.9])$ or that were restricted to interventions conducted in high-income countries (0.5 [0.4-0.6]).

Two sexual debut outcomes were not included in the meta-analysis. In addition to assessing initiation of vaginal or anal intercourse (the measure considered above), PREPARE examined a broader definition of sexual debut that included oral sex as well as vaginal and anal sex, and found no benefits from the intervention at either time point. ${ }^{62}$ The sexual debut outcome (i.e., lifetime sexual activity) from the Seattle Social Development Project (SSDP) was not included in the pooled analysis because the U.S. study used a quasi-experimental design. SSDP was a three-armed trial in which students from 17 schools received either the "full" intervention (from first to sixth grade) or a "late" intervention (only in fifth and sixth grades), or attended control schools. ${ }^{58}$ At six years postintervention, the proportion of students who reported having ever had sex was 11 percentage points lower in the full intervention group than in the control group. Outcomes did not differ between students receiving the late intervention and those in the control arm.

We could not perform meta-analyses for the remaining outcomes in studies of school-level environment interventions because the number of studies or information on effect sizes was insufficient. Instead, we summarize the findings narratively. The studies examined four sexual behavior outcomes: whether respondents had had sex recently; the frequency of sex; whether sex had been protected (condoms or contraceptives had been used); and number of sexual partners. The Aban Aya Project, which was the only study to measure recent engagement in sexual intercourse (though "recent" was undefined), was a three-armed randomized trial conducted in the United States; it compared a school and community intervention, a social development curriculum and a standard health curriculum control group. ${ }^{55}$ The researchers reported that three years after baseline, male students in the school and community arm were less likely than their counterparts in the control group to have had recent sexual intercourse (coefficient from generalized estimating equation, 0.7); no effects were evident, however, among female students. PREPARE was the only study to measure frequency of vaginal or anal sex, and it found no effects six or 12 months after baseline. ${ }^{62}$

Two randomized trials $s^{55,62}$ and one quasi-experimental study ${ }^{60,61}$ reported mixed results regarding protected sexual intercourse. Three years after baseline, male students in the Aban Aya school and community arm reported proportionately more condom use "all the time" than did those in the control group (coefficient from generalized estimating equation, 0.7), but no effects were found among female students. ${ }^{55}$ Youth who had received the full intervention in the quasi-experimental SSDP study were more likely than comparison students to report at the nine-year follow-up that they had used condoms at last intercourse (odds ratio, 1.9). ${ }^{60,61}$ The study reports did not indicate whether this association was related to increases in overall sexual activity. No associations were found for condom use at first sex (SSDP), condom or contraceptive use at last sex (PREPARE) or frequency of condom use (PREPARE and SSDP) ${ }^{60-62}$

One randomized trial $^{62}$ and one quasi-experimental study ${ }^{58,61}$ reported findings for measures of number of sexual partners. In the PREPARE trial, the intervention and comparison groups did not differ in this outcome six or 12 months after baseline. ${ }^{62}$ In the SSDP study, six years after the intervention, the proportion of students who reported having had more than one sexual partner by age 18 was 12 percentage points lower in the full intervention schools than in control schools; the late-intervention group did not differ from the control group. ${ }^{58}$ At the nine-year follow-up, the effects of the intervention remained evident among the full-intervention students in analyses that measured number of partners as a continuous variable. ${ }^{61}$

The SSDP study was the only evaluation of a schoollevel environment intervention to report outcomes related to pregnancies, births or STDs. ${ }^{58-61}$ At six years postintervention, no differences were evident in the pregnancy or birth rate between the full- or late-intervention and control groups. ${ }^{58}$ Nine years after the intervention, females in the full intervention group were less likely than those in the control group to report having ever been pregnant (odds ratio, 0.5 ) or having had a birth (0.4); no differences were observed among male participants in causing a pregnancy or fathering a child. ${ }^{60,61}$ At the same time point, the 
full-intervention and control groups did not differ in their lifetime rates of STDs; at 18 years postintervention, the full-intervention participants were less likely than participants in the control group to report having ever had an STD (0.3), but the late-intervention and control groups did not differ from each other. ${ }^{59}$

Three studies of school-level environment interventions reported academic or school-related outcomes (not shown). In the Gatehouse Project, students in the intervention group were less likely than those in the control group to have low school attachment, but the difference was statistically significant only in the last of the three cross-sectional samples. ${ }^{67}$ Higher rates of good academic behavior (e.g., working hard, setting goals, solving problems) were reported by students and their teachers in the intervention arm of the Positive Action study than by those in the control arm. ${ }^{65}$ Additional analysis revealed that such academic behavior partially mediated the intervention's effect on sexual debut. The SSDP study measured a number of academic variables when students were age 18 (six years postintervention) and found mixed results. ${ }^{58}$ Students who received the full intervention reported stronger commitment and attachment to school, and greater academic achievement, than did youth in the control group; their mean grade point average was higher as well, though the difference fell slightly short of statistical significance. Youth in the intervention and control groups did not differ in their likelihood of dropping out of school or in their standardized test scores, and no differences in any outcome were evident between the late-intervention and control groups.

\section{Student-Level Educational Assets Interventions}

Six of the 11 interventions were related to student-level educational assets. Two of these were cash transfer programs in which female students and their families received a monthly allowance either unconditionally ${ }^{51}$ or on the condition that they had attended school on at least $75-80 \%$ of school days in the previous month, ${ }^{50,51,64}$ the investigators hypothesized that these programs would reduce economic risk, and thus improve school attendance and sexual health outcomes. Four interventions subsidized expenses by paying school fees f $^{50,51,53,56,57}$ or by providing uniforms s3,54,56,57 $^{53,56,57}$ or additional supplies (e.g., pens, sanitary napkins). ${ }^{53,56,57}$ Three interventions provided support or case-management services to students, including access to adults who assisted students with absenteeism problems $s^{53,56,57,66}$ and support in setting academic and career goals. ${ }^{66}$

We could not conduct a meta-analysis of outcomes from interventions targeting student educational assets because of missing information and variability in reporting overall effect sizes; the results of these studies are thus synthesized narratively. All of the studies reported at least one sexual behavior outcome, such as sexual debut or engagement in protected sexual intercourse. Five randomized trials reported outcomes related to sexual debut during the intervention period, ${ }^{50,51,53,56,57}$ immediately after the intervention ${ }^{53,56,57,64}$ or at long-term follow-up. ${ }^{54}$ None of the studies found differences in these outcomes between the intervention and control groups.

Three trials reported on measures of protected and unprotected sex. ${ }^{51,54,64}$ Only one, a cash transfer program based in South Africa, reported a small intervention effect: At 12 months after baseline, youth in the intervention group were less likely than those in the control group to report having had unprotected sex in the past three months (relative risk, 0.8). ${ }^{64}$ The three trials also examined partnerrelated variables, and two found a significant intervention effect. Among a subgroup of Malawian females who had been attending school at baseline, those in the cash transfer group were less likely than those in the control group to report having a sexual partner older than 25 (odds ratio, 0.2). ${ }^{51}$ However, no difference was observed among females who were out of school at baseline. The cash transfer program in South Africa found that at follow-up, recipients were less likely than participants in the control group to have had any sex partner in the past 12 months, though no differences were apparent in measures of partner age or partner age difference. ${ }^{64}$ The third study, the Kenya Education Subsidy Program-a large randomized trial examining the effects of educational subsidies-found that at seven years postintervention the age of participants' oldest partner did not differ between the intervention and comparison groups. ${ }^{54}$

Sexual health outcomes-pregnancy, parenthood and STDs-were reported in four randomized trials ${ }^{50,51,54,57,64}$ and one quasi-experimental study. ${ }^{66}$ The two cash transfer programs reported no intervention effects on current pregnancy at 12 months postbaseline in Malawi ${ }^{50,51}$ or on any pregnancy during the study period in South Africa. ${ }^{64}$ The Kenyan subsidy program resulted in fewer lifetime pregnancies three years (mean difference, three percentage points) and five years (four percentage points) after the intervention among intervention participants compared to the control group, though no difference was apparent at seven years; among males, no differences in having caused a lifetime pregnancy were evident between groups at any time point. ${ }^{54}$ Only two pregnancies (both within the control group) occurred during the two-year randomized trial of the Zimbabwe School Support Program, so an effect size was not reported. ${ }^{57}$ In the only quasi-experimental educational assets study - the Promise Place Program, conducted in the United States-young women who had been pregnant at baseline were more likely to report that they were not pregnant at the 24-month follow-up if they had been in the intervention group (90\%) rather than in the control group (66\%), but no difference was found among young women who were already parents at baseline. ${ }^{66}$ These findings should be interpreted cautiously, however, as the study included only one treatment school and one comparison school, and the proportion of participants who were pregnant and parenting differed across treatment arms.

The two cash transfer trials and the Kenyan educational subsidy trial reported prevalence of STDs-HIV, herpes simplex virus 2 (HSV-2) and syphilis-measured 
via biomarkers among either a random subsample $e^{51,64}$ or all participants. ${ }^{54}$ In the Malawi cash transfer trial, among young women who had been enrolled in school at baseline, those in the intervention group were less likely than their counterparts in the control group to test positive for HIV (odds ratio, 0.4) or HSV-2 (0.2) 18 months after baseline. ${ }^{51}$ No effects on HIV or HSV-2 were found among participants who had dropped out of school at baseline, or on syphilis among participants in either subgroup. The South African cash transfer program tested for HIV and HSV-2 at baseline and at 12, 24 and 36 months (or until graduation, if it occurred before the end of the trial); no effects were apparent for either STD. ${ }^{64}$ The Kenyan subsidy trial collected biomarker data from participants seven years after the intervention; again, no differences were found between intervention and control groups for HIV or HSV-2 among either female or male participants. ${ }^{54}$

All six studies that examined student-level educational assets reported on academic outcomes or school-related measures (not shown). In three randomized trials, students in the intervention group were more likely to still be enrolled in school at follow-up, ${ }^{51}$ less likely to drop out of school ${ }^{54,57}$ or more likely to reach the eighth grade ${ }^{54}$ than were youth in control arms. An exception was the South African cash transfer program, which did not have any effects on dropout or attendance. ${ }^{64}$ Similarly, no differences in attendance between groups were evident in the Kenya Education Subsidy Program, though benefits were found for all other academic outcomes in this large study. ${ }^{54}$ Effects on absenteeism were mixed in two small, randomized trials. ${ }^{56,57}$ Finally, the quasi-experimental Promise Place study reported that a lower proportion of intervention students than control students dropped out among those who had been parenting-but not among those who had been pregnant-at baseline. ${ }^{66}$

\section{DISCUSSION}

Eleven outcome evaluations were included in this systematic review. Five studies assessed interventions that were related to the school-level environment and that, in particular, sought to change the school climate and culture through action teams and teacher training. The remaining six studies evaluated interventions designed to improve student-level educational assets; most of these programs provided financial incentives to increase school enrollment and attendance. Although all but two studies were randomized trials, poor reporting made quality assessment difficult, and in many studies, and across many domains, we were not able to clearly determine the risk of bias.

Our findings offer insights into whether the theory of human functioning and school organization might apply to sexual behaviors and sexual health outcomes. The theory posits that health behaviors can be improved by increasing students' commitment to school, specifically by breaking down boundaries between school and the surrounding community, strengthening teacher-student and peer relationships, and increasing student-centered learning. ${ }^{22}$
Findings from the meta-analysis of the effects of schoollevel environment interventions on sexual debut, along with the findings on recent sex and condom use from the Aban Aya trial, provide some support for the theory. School-level environment interventions employed school action teams to improve school climate, ${ }^{55,62,63}$ engaged young people in schoolwide activities ${ }^{55,62,63}$ and conducted teacher training to improve student-teacher relationships and strengthen student-centered learning. ${ }^{58-61,63}$ These practices are congruent with evidence from observational and evaluation studies suggesting that teacher and school support, academic support and mentoring, and school and class restructuring are important for students' academic performance ${ }^{68}$ and completion. ${ }^{69}$ This evidence aligns with and supports the theory's contention that increasing students' commitment to school will encourage them to behave in ways that accord with the prosocial values of these institutions. In addition, findings on educational outcomes from three studies support the notion that intervention effects on attachment and commitment to school, and on academic behavior and achievement, may serve a mediating or synergistic role in improving sexual health outcomes, further supporting the theory of human functioning and school organization. ${ }^{58,65,67}$ However, more data from rigorous evaluations are needed to assess the causal roadmap from school commitment to sexual health outcomes within school-level environment interventions, including whether these interventions improve educational outcomes.

Evidence for the effectiveness of school-level environmental interventions in improving other behavioral and health outcomes, including STDs and pregnancy, was mixed, and inconsistency in the outcomes measured across studies precluded meta-analysis. PREPARE was the only school-level environment intervention to demonstrate no effects on sexual behavior. ${ }^{62}$ This intervention, which was evaluated in South Africa, differed substantially from the other school-level environment interventions in both setting and purpose. PREPARE sought to improve school policies and practices specifically related to sexual violence and school safety, which the authors suggest were not sufficient to overcome structural and economic barriers to sexual health. Findings from this study might raise the question of whether the theory of human functioning and school organization is applicable mainly to high-income countries, such as the United States and Australia, where educational and economic opportunities are more readily available and culturally acceptable. ${ }^{70,71}$ However, it is also possible that the PREPARE intervention did not sufficiently align with constructs within the theory to provide an adequate empirical test.

Studies of interventions that address student-level educational assets provide less support for the theory of human functioning and school organization. Narrative synthesis suggests that the evidence is mixed as to whether these interventions, most of which provided financial support, can prevent pregnancies and STDs or reduce sexual risk behavior. For example, two large randomized trials each 
found an effect on either pregnancy ${ }^{54}$ or STDs, ${ }^{51}$ but not both. These studies also had significant impacts on rates of dropout ${ }^{54}$ and enrollment, ${ }^{51}$ which aligns with observational evidence that enrollment is important for sexual health outcomes. ${ }^{41,42}$ However, the remaining studies demonstrated very few effects on measures of pregnancy, STDs or sexual behaviors. Across studies, our narrative synthesis found no clear pattern of how interventions did or did not impact educational outcomes or sexual behavior and health. This might be explained in part by the limitations described below.

\section{Limitations}

Some limitations of the interventions and evaluations, as well as of our analysis, may have hindered our ability to assess the theory of human functioning and school organization in the context of sexual health. In some studies-particularly of interventions targeting studentlevel educational assets-differences between treatment groups may have been masked by sample sizes that were inadequate to detect effects ${ }^{53,56,57}$ or by contextual factors (such as the availability of subsidies, unrelated to the intervention, to students in the control group). ${ }^{56,64}$ Other studies may have been limited by a singular focus on increasing enrollment, and thus failed to address or overcome other factors important for sexual decision making, such as cultural norms that devalue females' education and sexual autonomy, support early marriage and stigmatize access to sexual health information. ${ }^{72,73}$ Most interventions to promote student-level educational assets did not address the impact on sexual health outcomes of other components of schooling, such as education quality or school climate, thus limiting their relevance to empirical assessment of many components of the theory of human functioning and school organization.

The usefulness of student-level intervention studies in assessing the theory was further limited by the fact that, while financial incentives and subsidies may improve school enrollment and attendance, they also tend to improve the economic position of students and their families. ${ }^{74}$ Since pregnancy and other sexual health outcomes are associated with family- and community-level socioeconomic status, ${ }^{3}$ it is challenging to untangle the impact of school on sexual health outcomes from that of poverty alleviation in cash transfer and education subsidy programs. For example, an increase in income theoretically reduces the need for individuals to engage in transactional sex, thus possibly reducing the frequency of unprotected $\operatorname{sex}^{64}$ and the number of sexual partners. ${ }^{51,64}$ However, as one study in our analysis concluded, the benefits of cash transfers may not outweigh the social benefits of transactional sex. ${ }^{64}$ Interventions that provide financial incentives for school enrollment and attendance may be strengthened by targeting additional social and educational assets in school-based settings.

Furthermore, the transferability of evidence across settings was difficult to determine given that all but one of the studies of interventions related to school-level environment were conducted in high-income countries, and all but one of the studies of interventions related to student-level educational assets were conducted in middle- or low-income countries. Economic and cultural differences among countries may have affected the intervention components addressing school-related factors and how these components were received by participants. These differences could have been further compounded by selection bias, a possible risk in trials in which blinding is not possible $;{ }^{75}$ however, the extent of this risk in the studies we examined is unclear because allocation concealment was poorly reported. Furthermore, although interventions related to educational assets did not include additional curriculum components, the majority of school-level environment interventions did, so that the effects of the school environment and those of curriculum components could not be disaggregated. However, results from the three-armed Aban Aya trial, in which one arm focused on a curriculum intervention and one on an intervention with curriculum and environment components, suggest that changes to the school environment had independent effects on sexual risk behaviors. ${ }^{55}$

Our review itself also has limitations. Although we did not deviate from the established protocol, we modified it at the start of full-text screening to clarify which interventions were to be included. Because the inclusion criteria for intervention type were broad during screening of titles and abstracts, these modifications did not affect initial screening; however, some potentially relevant studies may have been excluded during screening of full reports if the interventions were insufficiently described. Although we sought to minimize location and language bias by searching multiple databases without language restrictions, it is possible that our exclusion of studies published prior to 1990 resulted in our missing some relevant research; however, because all of the studies we identified were published after 1998, and most were published within the past 10 years, we feel this cutoff was generous and reasonable. We were unable to assess publication bias owing to the small number of studies.

Given the variability in how data were reported, which is common in studies of social interventions, ${ }^{76}$ analysis required transformation of data into standardized effects for school-level environment studies. Because several studies did not provide adequate information to standardize effect sizes or provided effect data only for subgroups of participants, we were unable to undertake meta-analyses of educational asset outcomes and most school-level environment outcomes. In the majority of cases, e-mails to authors for missing data were not answered. As a result of these issues, only a single meta-analysis was possible, and we could not conduct meta-regression analysis to explore the heterogeneity of effects.

Finally, while this review focused on interventions aimed at school-level environment and student-level educational assets to potentially illuminate the theory of human functioning and school organization, ${ }^{22}$ we were disappointed to find that no studies addressed both school- and studentlevel domains simultaneously. 


\section{Implications for Policy and Research}

Our findings are generally consistent with those of other reviews examining school-level environment interventions, which concluded that evidence is insufficient to assess the probability that these programs improve sexual health. ${ }^{44,45}$ Unlike prior investigators, we were able to conduct a meta-analysis, the results of which suggest that interventions modifying aspects of the school environment, such as school climate or access to caring adults, have the potential to delay sexual debut. Our narrative synthesis indicates it is plausible that interventions aimed at improving studentlevel assets can be effective in reducing levels of pregnancy and STDs; this conclusion is supported by reviews that have examined the broader impacts of sexual health interventions in low- and middle-income countries. ${ }^{72,77,78}$ However, our analysis of the relationship between intervention effects on sexual behaviors and educational outcomes and those on pregnancy and STDs fails to reveal a clear pathway by which the interventions affect health outcomes. Because subsidy and cash transfer programs are expensive, ${ }^{77}$ ample opportunity exists for new research to explore the causal mechanisms of these programs, as well as any added benefits to combining these programs with other intervention components known to improve sexual health.

More rigorous evaluation is needed to determine the effects of school-environment interventions on long-term sexual health outcomes, including pregnancy and STDs. Investigators studying interventions that modify school environment and educational assets should more clearly conceptualize the mechanisms of change, and assess the relationships between school-related outcomes and sexual behavior and health. The theory of human functioning and school organization provides a useful starting point for identifying processes by which school-based and educational interventions may work to influence sexual behavior. Cash transfer and educational subsidy programs may consider how commitment to school prior to receiving financial support influences long-term outcomes, and whether these programs may have synergistic effects if combined with elements of school-environment interventions, such as those that address school climate or studentteacher relationships. As other reviews have concluded, ${ }^{45}$ studies should compare these interventions with and without curriculum components. Specifically, future research might collect more detailed information on the components of such complex interventions, and their implementation, to support greater understanding of how each component contributes independently or interdependently to improve outcomes. Finally, future reviews would greatly benefit from improved reporting on risk of bias domains.

\section{REFERENCES}

1. Sedgh $G$ et al., Adolescent pregnancy, birth, and abortion rates across countries: levels and recent trends, Journal of Adolescent Health, 2015, 56(2):223-230, https://doi.org/10.1016/j.jadohealth.2014.09.007.

2. Kost $\mathrm{K}$ and Henshaw S, U.S. Teenage Pregnancies, Births and Abortions, 2010: National and State Trends and Trends by Age, Race and Ethnicity, New York: Guttmacher Institute, 2014.
3. Penman-Aguilar A et al., Socioeconomic disadvantage as a social determinant of teen childbearing in the U.S, Public Health Reports, 2013, 128(2 Suppl. 1):5-22, https://doi.org/10.1177/003335491312 $82 \mathrm{~S} 102$.

4. Wellings $\mathrm{K}$ et al., Changes in conceptions in women younger than 18 years and the circumstances of young mothers in England in 2000-12: an observational study, Lancet, 2016, 388(10044):586-595, https://doi.org/10.1016/S0140-6736(16)30449-4.

5. Dehne K and Riedner G, Sexually Transmitted Infections Among Adolescents: The Need for Adequate Health Services, Geneva: World Health Organization, 2005.

6. Kann L et al., Youth Risk Behavior Surveillance-United States, 2017, MMWR. Surveillance Summaries, 2018, 67:8, https://doi. org/10.15585/mmwr.ss6708al.

7. Kipping RR et al., Multiple risk behaviour in adolescence and socioeconomic status: findings from a UK birth cohort, European Journal of Public Health, 2015, 25(1):44-49, https://doi.org/10.1093/eurpub/ cku078.

8. Lewis $\mathrm{R}$ et al., Heterosexual practices among young people in Britain: evidence from three national surveys of sexual attitudes and lifestyles, Journal of Adolescent Health, 2017, 61(6):694-702, https:// doi.org/10.1016/j.jadohealth.2017.07.004.

9. United Nations Educational, Scientific and Cultural Organization (UNESCO), Emerging Evidence, Lessons and Practice in Comprehensive Sexuality Education: A Global Review, Paris: UNESCO, 2015.

10. DiCenso A et al., Interventions to reduce unintended pregnancies among adolescents: systematic review of randomised controlled trials, BMJ, 2002, 324:1426, https://doi.org/10.1136/bmj.324.7351.1426.

11. Marseille E et al., Effectiveness of school-based teen pregnancy prevention programs in the USA: a systematic review and meta-analysis, Prevention Science, 2018, 19(4):468-489, https://doi.org/10.1007/ s11121-017-0861-6.

12. Kirby D, The impact of schools and school programs upon adolescent sexual behavior, Journal of Sex Research, 2002, 39(1):27-33, https://doi.org/10.1080/00224490209552116.

13. Rose G, Rose's Strategy of Preventive Medicine, Oxford, UK: Oxford University Press, 1992.

14. Viner $\mathrm{R}$ et al., Adolescence and the social determinants of health, Lancet, 2012, 379(9826):1641-1652, https://doi.org/10.1016/S01406736(12)60149-4.

15. Forman SG et al., Evidence-based interventions in schools: developers' views of implementation barriers and facilitators, School Mental Health, 2009, 1(1):26-36, https://doi.org/10.1007/s12310-0089002-5.

16. Hadley A, Ingham R and Chandra-Mouli V, Implementing the United Kingdom's 10-year teenage pregnancy strategy for England (1999-2010): How was this done and what did it achieve? Reproductive Health, 2016, 13:139, https://doi.org/10.1186/s12978-016-0255-4.

17. Landry DJ et al., Factors associated with the content of sex education in U.S. public secondary schools, Perspectives on Sexual and Reproductive Health, 2003, 35(6):261-269, https://doi.org/10.1363/3526103.

18. Braveman P, Egerter $S$ and Williams DR, The social determinants of health: coming of age, Annual Review of Public Health, 2011, 32:381-398, https://doi.org/10.1146/annurev-publhealth031210-101218.

19. Benson P, Developmental assets: an overview of theory, research, and practice, in: Silbereisen RK and Lerner RM, eds., Approaches to Positive Youth Development, Thousand Oaks, CA: SAGE, 2007.

20. Hawkins JD and Weis JG, The social development model: an integrated approach to delinquency prevention, Journal of Primary Prevention, 1985, 6(2):73-97, https://doi.org/10.1007/BF01325432. 
21. Bonell $\mathrm{C}$ et al., Theories of how the school environment impacts on student health: systematic review and synthesis, Health \& Place, 2013, 24:242-249, https://doi.org/10.1016/j.healthplace.2013.09.014.

22. Markham WA and Aveyard P, A new theory of health promoting schools based on human functioning, school organisation and pedagogic practice, Social Science \& Medicine, 2003, 56(6):1209-1220, https://doi.org/10.1016/S0277-9536(02)00120-X.

23. Aveyard P et al., The influence of school culture on smoking among pupils, Social Science \& Medicine, 2004, 58(9):1767-1780, https://doi.org/10.1016/S0277-9536(03)00396-4.

24. Bonell C et al., Student- and school-level belonging and commitment and student smoking, drinking and misbehaviour, Health Education Journal, 2016, 76(2):206-220, https://doi.org/10.1177/0017896916657843.

25. Markham WA et al., Value-added education and smoking uptake in schools: a cohort study, Addiction, 2008, 103(1):155-161, https:// doi.org/10.1111/j.1360-0443.2007.02020.x.

26. Markham WA et al., Does school ethos explain the relationship between value-added education and teenage substance use? A cohort study, Social Science \& Medicine, 2012, 75(1):69-76, https://doi. org/10.1016/j.socscimed.2012.02.045.

27. McNeely $C$ and Falci C, School connectedness and the transition into and out of health-risk behavior among adolescents: a comparison of social belonging and teacher support, Journal of School Health, 2004, 74(7):284-292, https://doi.org/10.1111/j.1746-1561.2004.tb08285.x.

28. Baumer E and South S, Community effects on youth sexual activity, Journal of Marriage and the Family, 2001, 63(2):540-554, https:// doi.org/10.1111/j.1741-3737.2001.00540.x.

29. Paul $\mathrm{C}$ et al., The determinants of sexual intercourse before age 16, Journal of Adolescent Health, 2000, 27(2):136-147, https://doi. org/10.1016/S1054-139X(99)00095-6.

30. South S and Baumer E, Deciphering community and race effects on adolescent premarital childbearing, Social Forces, 2000, 78(4):13791407, https://doi.org/10.1093/sf/78.4.1379

31. Rink E, Tricker R and Harvey SM, Onset of sexual intercourse among female adolescents: the influence of perceptions, depression, and ecological factors, Journal of Adolescent Health, 2007, 41(4):398406, https://doi.org/10.1016/j.jadohealth.2007.04.017.

32. McBride CM et al., School-level application of a social bonding model to adolescent risk-taking behavior, Journal of School Health, 1995, 65(2):63-68, https://doi.org/10.1111/j.1746-1561.1995.tb03347.x.

33. Miller KE et al., Athletic participation and sexual behavior in adolescents: the different worlds of boys and girls, Journal of Health and Social Behavior, 1998, 39(2):108-123, https://doi.org/10.2307/2676394.

34. Sabo DF et al., High school athletic participation, sexual behavior and adolescent pregnancy: a regional study, Journal of Adolescent Health, 1999, 25(3):207-216, https://doi.org/10.1016/S1054-139X(99)00070-1.

35. Lauritsen J, Explaining race and gender differences in adolescent sexual behavior, Social Forces, 1994, 72(3):859-883, https://doi. org/10.1093/sf/72.3.859.

36. Bonell $\mathrm{C}$ et al., The effect of dislike of school on risk of teenage pregnancy: testing of hypotheses using longitudinal data from a randomised trial of sex education, Journal of Epidemiology and Community Health, 2005, 59(3):223-230, https://doi.org/10.1136/ jech.2004.023374.

37. Kogan SM et al., Avoiding adolescent pregnancy: a longitudinal analysis of African-American youth, Journal of Adolescent Health, 2013, 53(1):14-20, https://doi.org/10.1016/j.jadohealth.2013.01.024

38. Henderson $\mathrm{M}$ et al., What explains between-school differences in rates of sexual experience? BMC Public Health, 2008, 8:53, https://doi. org/10.1186/1471-2458-8-53.
39. White CN and Warner LA, Influence of family and school-level factors on age of sexual initiation, Journal of Adolescent Health, 2015, 56(2):231-237, https://doi.org/10.1016/j.jadohealth.2014.09.017

40. House LD et al., Competence as a predictor of sexual and reproductive health outcomes for youth: a systematic review, Journal of Adolescent Health, 2010, 46(3 Suppl.):S7-S22, https://doi.org/10.1016/j.jadohealth.2009.12.003.

41. Rosenberg M et al., Relationship between school dropout and teen pregnancy among rural South African young women, International Journal of Epidemiology, 2015, 44(3):928-936, https://doi.org/10.1093/ ije/dyv007.

42. Glynn JR et al., Early school failure predicts teenage pregnancy and marriage: a large population-based cohort study in northern Malawi, PLoS One, 2018, 13(5):e0196041, https://doi.org/10.1371/ journal.pone.0196041.

43. Harman L et al., Cash Transfers: What Does the Evidence Say? London: Overseas Development Institute, 2016, https://www.odi.org/ sites/odi.org.uk/files/resource-documents/10747.pdf.

44. Langford $\mathrm{R}$ et al., The WHO Health Promoting School framework for improving the health and well-being of students and their academic achievement, Cochrane Database of Systematic Reviews, 2014, Issue 4, No. CD008958, https://doi.org/10.1002/14651858. CD008958.pub2.

45. Bonell $\mathrm{C}$ et al., The effects on student health of interventions modifying the school environment: systematic review, Journal of Epidemiology and Community Health, 2013, 67(8):677-681, https://doi.org/10.1136/ jech-2012-202247.

46. Gavin LE et al., A review of positive youth development programs that promote adolescent sexual and reproductive health, Journal of Adolescent Health, 2010, 46(3 Suppl.):S75-S91, https://doi. org/10.1016/j.jadohealth.2009.11.215.

47. Moher D et al., Preferred reporting items for systematic reviews and meta-analyses: the PRISMA statement, PLoS Medicine, 2009, 6(7):e1000097, https://doi.org/10.1371/journal.pmed.1000097.

48. Higgins JPT and Green S, eds., Cochrane Handbook for Systematic Reviews of Interventions, version 5.1.0, London: Cochrane Collaboration, 2011

49. Shepherd J et al., The effectiveness and cost-effectiveness of behavioural interventions for the prevention of sexually transmitted infections in young people aged 13-19: a systematic review and economic evaluation, Health Technology Assessment, 2010, 14:7, https://doi. org/10.3310/htal4070.

50. Baird SJ et al., The short-term impacts of a schooling conditional cash transfer program on the sexual behavior of young women, Health Economics, 2010, 19(Suppl. 1):55-68, https://doi.org/10.1002/hec.1569.

51. Baird SJ et al., Effect of a cash transfer programme for schooling on prevalence of HIV and herpes simplex type 2 in Malawi: a cluster randomised trial, Lancet, 2012, 379(9823):1320-1329, https://doi. org/10.1016/S0140-6736(11)61709-1

52. Beets MW et al., Use of a social and character development program to prevent substance use, violent behaviors, and sexual activity among elementary-school students in Hawaii, American Journal of Public Health, 2009, 99(8):1438-1445, https://doi.org/10.2105/ AJPH.2008.142919.

53. Cho $\mathrm{H}$ et al., Keeping adolescent orphans in school to prevent human immunodeficiency virus infection: evidence from a randomized controlled trial in Kenya, Journal of Adolescent Health, 2011, 48(5):523526, https://doi.org/10.1016/j.jadohealth.2010.08.007.

54. Duflo E, Dupas P and Kremer M, Education, HIV, and early fertility: experimental evidence from Kenya, American Economic Review, 2015, 105(9):2757-2797, https://doi.org/10.1257/aer.20121607.

55. Flay BR et al., Effects of 2 prevention programs on high-risk behaviors among African American youth: a randomized trial, Archives 
of Pediatrics \& Adolescent Medicine, 2004, 158(4):377-384, https://doi. org/10.1001/archpedi.158.4.377.

56. Hallfors DD et al., Process and outcome evaluation of a community intervention for orphan adolescents in western Kenya, Journal of Community Health, 2012, 37(5):1101-1109, https://doi.org/10.1007/ s10900-012-9548-x.

57. Hallfors DD et al., Supporting adolescent orphan girls to stay in school as HIV risk prevention: evidence from a randomized controlled trial in Zimbabwe, American Journal of Public Health, 2011, 101(6):1082-1088, https://doi.org/10.2105/AJPH.2010.300042.

58. Hawkins JD et al., Preventing adolescent health-risk behaviors by strengthening protection during childhood, Archives of Pediatrics $\&$ Adolescent Medicine, 1999, 153(3):226-234, https://doi.org/10.1001/ archpedi.153.3.226.

59. Hill KG et al., The onset of STI diagnosis through age 30: results from the Seattle Social Development Project intervention, Prevention Science, 2014, 15(1 Suppl.):S19-S32, https://doi.org/10.1007/s11121-013-0382-x.

60. Lonczak HS, An examination of the long-term effects of the Seattle Social Development Project on sexual behavior and related outcomes, and of the consequences of adolescent motherhood, unpublished dissertation, Seattle: University of Washington, 2000.

61. Lonczak HS et al., Effects of the Seattle Social Development Project on sexual behavior, pregnancy, birth, and sexually transmitted disease outcomes by age 21 years, Archives of Pediatrics $\&$ Adolescent Medicine, 2002, 156(5):438-447, https://doi.org/10.1001/archpedi.156.5.438.

62. Mathews $C$ et al., Effects of PREPARE, a multi-component, schoolbased HIV and intimate partner violence (IPV) prevention programme on adolescent sexual risk behaviour and IPV: cluster randomised controlled trial, AIDS and Behavior, 2016, 20(9):1821-1840, https://doi. org/10.1007/s10461-016-1410-1.

63. Patton GC et al., Promoting social inclusion in schools: a grouprandomized trial of effects on student health risk behavior and well-being, American Journal of Public Health, 2006, 96(9):1582-1587, https://doi.org/10.2105/AJPH.2004.047399.

64. Pettifor A et al., The effect of a conditional cash transfer on HIV incidence in young women in rural South Africa (HPTN 068): a phase 3, randomised controlled trial, Lancet Global Health, 2016, 4(12):e978-e988, https://doi.org/10.1016/S2214-109X(16)30253-4.

65. Snyder FJ et al., Preventing negative behaviors among elementaryschool students through enhancing students' social-emotional and character development, American Journal of Health Promotion, 2013, 28(1):50-58, https://doi.org/10.4278/ajhp.120419-QUAN-207.2.

66. Tolma EL et al., Longitudinal evaluation of a teenage pregnancy case management program in Oklahoma, Journal of Family Social Work, 2014, 17(5):457-479, https://doi.org/10.1080/10522158.2014.940634.
67. Bond L et al., The Gatehouse Project: Can a multilevel school intervention affect emotional wellbeing and health risk behaviours? Journal of Epidemiology and Community Health, 2004, 58(12):997-1003, https://doi.org/10.1136/jech.2003.009449.

68. Banerjee PA, A systematic review of factors linked to poor academic performance of disadvantaged students in science and maths in schools, Cogent Education, 2016, 3:1178441, https://doi.org/10.1080/2 331186X.2016.1178441.

69. Hahn RA et al., Programs to increase high school completion, American Journal of Preventive Medicine, 2015, 48(5):599-608, https:// doi.org/10.1016/j.amepre.2014.12.005.

70. Narayan A et al., Fair Progress? Economic Mobility Across Generations Around the World, Washington, DC: World Bank, 2018.

71. World Bank, World Development Report 2018: Learning to Realize Education's Promise, Washington, DC: World Bank, 2018.

72. McQueston K, Silverman A and Glassman A, Adolescent fertility in low- and middle-income countries: effects and solutions, Working Paper, Washington, DC: Center for Global Development, 2012, No. 295.

73. Morris JL and Rushwan H, Adolescent sexual and reproductive health: the global challenges, International Journal of Gynaecology \& Obstetrics, 2015, 131(Suppl. 1):S40-S42, https://doi.org/10.1016/j. ijgo.2015.02.006

74. Fiszbein A et al., Conditional Cash Transfers: Reducing Present and Future Poverty, Washington, DC: World Bank, 2009.

75. Kahan BC, Rehal $S$ and Cro S, Risk of selection bias in randomised trials, Trials, 2015, 16:405, https://doi.org/10.1186/s13063-0150920-x.

76. Grant $\mathrm{S}$ et al., Developing a reporting guideline for social and psychological intervention trials, Research on Social Work Practice, 2013, 23(6):595-602, https://doi.org/10.1177/1049731513498118.

77. Hindin MJ et al., Interventions to prevent unintended and repeat pregnancy among young people in low- and middle-income countries: a systematic review of the published and gray literature, Journal of Adolescent Health, 2016, 59(3 Suppl.):S8-S15, https://doi. org/10.1016/j.jadohealth.2016.04.021.

78. Kalamar AM, Bayer AM and Hindin MJ, Interventions to prevent sexually transmitted infections, including HIV, among young people in low- and middle-income countries: a systematic review of the published and gray literature, Journal of Adolescent Health, 2016, 59(3 Suppl.):S22-S31, https://doi.org/10.1016/j.jadohealth.2016. 05.020 .

Author contact: amy.peterson@etr.org 
TABLE 1. Selected characteristics of studies included in the systematic analysis of the effects of interventions addressing school environments or educational assets on adolescent sexual health

\begin{tabular}{|c|c|c|c|c|}
\hline Intervention & Intervention description & Study design and sample & Participant characteristics & Outcomes \\
\hline \multicolumn{5}{|l|}{$\begin{array}{l}\text { School-environment } \\
\text { studies }\end{array}$} \\
\hline $\begin{array}{l}\text { Aban Aya Youth Proj- } \\
\text { ect, United States }{ }^{55}\end{array}$ & $\begin{array}{l}\text { Based on theory of triadic influ- } \\
\text { ence, Aban Aya consisted of a } \\
\text { social development curriculum } \\
\text { and a school/community interven- } \\
\text { tion that aimed to reduce high-risk } \\
\text { behaviors by targeting risk and } \\
\text { protective factors, enhancing sense } \\
\text { of self and cognitive-behavioral } \\
\text { skills, and strengthening family and } \\
\text { community ties. The intervention } \\
\text { was intended to affect all social } \\
\text { domains that influence children } \\
\text { (family, school, community) by pro- } \\
\text { viding parental support, increasing } \\
\text { youth-support programs in school, } \\
\text { and forging links among parents, } \\
\text { schools and local businesses } \\
\text { through a school task force. }\end{array}$ & $\begin{array}{l}\text {-Randomized controlled trial } \\
\text {-Unit of randomization: School } \\
\text { - Baseline sample: Intervention } \\
\text { group had } 366 \text { students at } 4 \\
\text { schools; comparison group had } \\
372 \text { students at } 4 \text { schools } \\
\text {-Follow-up: } 3 \text { years postbaseline } \\
\text {-Attrition: } 20 \% \text { turnover each year; } \\
51 \% \text { of original sample completed } \\
\text { final follow-up }\end{array}$ & $\begin{array}{l}\text {-Mean age: } 11 \text { (5th grade) } \\
\text {-Gender: } 51 \% \text { female, } 49 \% \text { male } \\
\text {-Race/ethnicity: School popula- } \\
\text { tions were } 91 \% \text { African-American } \\
\text {-Socioeconomic status: } 77 \% \text { of stu- } \\
\text { dents received federally subsidized } \\
\text { school meals }\end{array}$ & $\begin{array}{l}3 \text { years postbaseline } \\
\text { •Recent sexual intercourse: } \\
\text { Males: Effect size from GEE, } 0.65^{*} \\
\text { Females: } \mathrm{ns} \\
\text {-Used a condom "all the time": } \\
\text { Males: Effect size from GEE, } 0.66^{*} \\
\text { Females: } \mathrm{ns}\end{array}$ \\
\hline $\begin{array}{l}\text { Gatehouse Project, } \\
\text { Australia }^{63}\end{array}$ & $\begin{array}{l}\text { Gatehouse's goal was to reduce risk } \\
\text { behaviors and improve emotional } \\
\text { well-being by promoting social } \\
\text { inclusion and commitment to } \\
\text { education. The intervention had } \\
\text { four components: a student survey } \\
\text { about security, school life and com- } \\
\text { munication with teachers; a school } \\
\text { action team focused on school pol- } \\
\text { icies and teacher practices; consul- } \\
\text { tation and training on intervention } \\
\text { strategies; and a 10-week social- } \\
\text { emotional curriculum. Strategies } \\
\text { varied among schools but always } \\
\text { addressed school policy, included } \\
\text { the curriculum and promoted } \\
\text { inclusive relationships within } \\
\text { the classroom. Intervention and } \\
\text { comparison groups each consisted } \\
\text { of three cross-sectional samples, } \\
\text { two years apart, all of which were } \\
\text { followed for four years. }\end{array}$ & $\begin{array}{l}\text {-Randomized controlled trial } \\
\text {-Unit of randomization: School } \\
\text {-Baseline sample: Intervention } \\
\text { group had } 966-1,343 \text { students } \\
\text { (number varied by year) at } 11 \\
\text { schools; comparison group had } \\
\text { 1,342-1,497 students at } 14 \text { schools } \\
\text {-Follow-up: } 2 \text { and } 4 \text { years } \\
\text { postbaseline } \\
\text {-Response rates: } 66-75 \%\end{array}$ & $\begin{array}{l}\text {-Age: } 13-14 \text { (8th grade) } \\
\text {-Gender: } 52-55 \% \text { female } \\
\text {-Race/ethnicity: Not stated } \\
\text {-Socioeconomic status: Not stated }\end{array}$ & $\begin{array}{l}2 \text { years postbaseline } \\
\text {-Ever had sex: } \\
\text { Odds ratio, } 0.8(0.6-1.2) \\
4 \text { years postbaseline } \\
\text {-Ever had sex: } \\
\text { Odds ratio, } 0.6(0.4-0.8)^{* * *}\end{array}$ \\
\hline $\begin{array}{l}\text { Positive Action, United } \\
\text { States }^{52,65}\end{array}$ & $\begin{array}{l}\text { Based on the theory of self- } \\
\text { concept, Positive Action was a } \\
\text { multicomponent, school-based } \\
\text { program designed to improve } \\
\text { student behaviors by strengthen- } \\
\text { ing school climate, relationships } \\
\text { and engagement in learning. The } \\
\text { program included a classroom cur- } \\
\text { riculum as well as family and com- } \\
\text { munity involvement components; } \\
\text { principals received a kit providing } \\
\text { directions for a schoolwide climate } \\
\text { program to promote the core } \\
\text { elements of the curriculum and to } \\
\text { encourage and reinforce positive } \\
\text { actions throughout the school. }\end{array}$ & $\begin{array}{l}\text {-Randomized controlled trial } \\
\text {-Unit of randomization: School } \\
\text {-Follow-up sample: Intervention } \\
\text { group had } 976 \text { students at } 10 \\
\text { schools; comparison group had } \\
738 \text { students at } 10 \text { schools } \\
\text {-Follow-up: } 5 \text { years postbaseline } \\
\text {-Attrition: Baseline sample size and } \\
\text { attrition not reported }\end{array}$ & $\begin{array}{l}\text {-Age: } 10-11 \text { (5th grade) } \\
\text {-Gender: } 50 \% \text { female, } 50 \% \text { male } \\
\text {-Race/ethnicity: } 26 \% \text { Hawaiian, } \\
23 \% \text { multiethnic, } 9 \% \text { white, } 5 \% \\
\text { other Pacific Islander, } 5 \% \text { Japanese, } \\
21 \% \text { other Asian, } 2 \% \text { Native } \\
\text { American, } 2 \% \text { black, } 8 \% \text { other, } 2 \% \\
\text { unknown } \\
\text {-Socioeconomic status: Not stated }\end{array}$ & $\begin{array}{l}5 \text { years postbaseline } \\
\text { - Lifetime sexual activity with } \\
\text { opposite gender: } \\
\text { Odds ratio, } 0.2(0.1-0.7)^{*}\end{array}$ \\
\hline
\end{tabular}

Table continues 


\section{TABLE 1 (continued)}

Intervention

Intervention description

Study design and sample

Participant characteristics

Outcomes

PREPARE, South Africa $^{62}$
PREPARE was a multicomponent intervention hypothesized to synergistically reduce sexual risk behaviors and intimate partner violence by providing social support and by changing norms. The intervention comprised a 21-session educational program, school health services delivered by a nurse and a school safety program. The latter had two components: Teams consisting of principals, teachers, school safety officers, parents and police officers attended a two-day training session on laws regarding sexual violence and on action plans for a school safety audit; and randomly selected students participated in a photovoice project (a qualitative method using photography, storytelling and discussion) to identify unsafe situations and places within the school.
-Randomized controlled trial - Unit of randomization: School -Baseline sample: Intervention group had 1,748 students at 20 schools; comparison group had 1,703 students at 22 schools -Follow-up: 6 and 12 months postbaseline

-Attrition: $6 \%$ at 6 months and $12 \%$

at 12 months
-Mean age: 13.7

-Gender: 58-62\% female -Race/ethnicity: Not stated

- Socioeconomic status: Mean score of 6.0 (standard deviation, 1.7) in both groups on an undefined socioeconomic index

\section{6 months postbaseline}

- Ever had vaginal or anal sex

Odds ratio, 1.0 (0.8-1.5)

-Ever had vaginal, anal or oral sex: Odds ratio, 1.2 (1.0-1.5)

-Vaginal sex frequency in last 6 months:

Beta, 0.12 ( -0.03 to 0.3 )

-Anal sex frequency in last 6 months: Beta, 0.02 ( -0.1 to 0.1 )

-Condom use at last sex

Odds ratio, 0.7 (0.4-1.4)

-Condom use frequency in last 6 months:

Beta, 0.1 ( -0.2 to 0.4$)$

-Contraceptive use (excluding condoms) at last sex:

Odds ratio, $1.2(0.7-2.3)$

- Lifetime number of partners.

Beta, 0.4 ( -0.4 to 1.0$)$

12 months postbaseline

- Ever had vaginal or anal sex

Odds ratio, 1.1 (0.8-1.4)

-Ever had vaginal, anal or oral sex:

Odds ratio, 1.1 (0.8-1.4)

-Vaginal sex frequency in last 6 months:

Beta, 0.08 ( -0.1 to 0.3 )

-Anal sex frequency in last 6 months:

Beta, 0.1 ( -0.02 to 0.3 )

-Condom use at last sex

Odds ratio, 0.6 (0.3-1.3)

-Condom use frequency in last

6 months:

Beta, -0.1 ( -0.4 to 0.3 )

-Contraceptive use (excluding con-

doms) at last sex:

Odds ratio, $1.2(0.7-2.1)$

- Lifetime number of partners:

Beta, -0.03 ( -0.7 to 0.6)

Table continues 
TABLE 1 (continued)

Intervention

Intervention description

Study design and sample

Participant characteristics

Outcomes

Seattle Social Develop- Based on the social development ment Project (SSDP),

model, SSDP was theorized to

-Quasi-experimental study

- Unit of study: School

-Mean age: 11 (5th grade) at baseline survey

reduce risk behaviors by increasing -Baseline sample: Intervention

student bonding to school via

teacher training, parent education

and social competence training.

Teachers received in-service

group had 156 students (full) and

267 students (late) at 12 schools:

comparison group had 220 stu-

dents at 5 schools

training on three instructional

-Follow-up: 6, 9 and 18 years

methods: proactive classroom

postintervention

engagement interactive teaching

and cooperative learning.

Attrition: $7 \%$ at 6 years, $7 \%$ at 9

years and $6 \%$ at 18 years

irst-grade teachers delivered a

cognitive and social skills training

curriculum. Students assigned

to the "full" intervention group

attended intervention schools

for grades 1-6; those in the "late"

intervention group attended such

schools in grades 5-6.

-Gender: $46-51 \%$ female in the

three groups

-Race/ethnicity: $47 \%$ white, $26 \%$

black, 21\% Asian, 7\% other

-Socioeconomic status: $56-59 \%$ of

students in the three groups were

enrolled in National School Lunch/

School Breakfast Program

\section{6 years postintervention}

Mean percentage-point difference

between intervention groups and

control group:

- Lifetime sexual intercourse:

Full intervention: $-10.9(-19.2$ to

$-1.4)^{*}$

Late intervention: -6.9 (-14.0 to

1.0)

- Lifetime multiple partners:

Full: -11.8 (-21.7 to -0.7$)^{*}$

Late: -2.4 (-11.1 to 7.2 )

-Ever pregnant:

Full: -9.3 (-17.3 to 0.0$)$

Late: 1.0 (-7.8 to 8.9$)$

-Ever gave birth:

Full: -7.3 (-15.4 to 2.0$)$

Late: 1.9 (-6.8 to 9.1 )

9 years postintervention

Comparison between full interven-

tion group and control group:

-Everhad sex:

Not reported

-Age at sexual debut

Mean difference, $-0.6(-1.1$ to

$-0.1)+$

- Condom use frequency in past year:

Mean difference (on a 1-5 scale)

-0.2 ( -0.6 to 0.2 )

-Condom use at last sex:

Odds ratio, $1.9(1.1-3.2)^{*}$

-Condom use at first sex:

Odds ratio, 1.4 (0.9-2.3)

-Number of partners:

Mean difference, $0.6(0.1-1.0)^{*}$

-Ever pregnant/caused a pregnancy:

Female: Odds ratio, 0.5 (0.3-0.9)*

Male: Odds ratio, 1.0 (0.5-1.8)

-Ever had birth/fathered a child:

Female: Odds ratio, $0.4(0.2-0.8)^{*}$

Male: Odds ratio, $1.2(0.6-2.5)$

- Ever had STD:

Odds ratio, 0.7 (0.4-1.3)

18 years postintervention

Comparison between intervention

groups and control group:

-Age at sexual debut:

Not reported

-Everhad STD

Full: Odds ratio, $0.3^{* *}$

Late: Odds ratio, 0.8

Table continues 
TABLE 1 (continued)

Intervention

Intervention description

Study design and sample

Participant characteristics

Outcomes

\section{Educational assets}

studies

Kenya Education Subsidy Program, Kenya ${ }^{54}$

The Kenya Education Subsidy intervention aimed to reduce adolescents' dropout, pregnancy and marriage rates by subsidizing the cost of education for upper primary school students, thereby reducing economic risk factors. $A$ free school uniform was distributed to each student at the beginning of grade 6 , and a second uniform was delivered a year later if the student was still enrolled in the same school. The subsidy, delivered over two years, totaled $\sim$ US\$12 pe student.
Kenya School Support Program, Kenya ${ }^{53,56}$

Promise Place Program, United States ${ }^{66}$
Based on the social development model, the Kenya School Support Program provided orphaned adolescents with financial support and counseling to increase attachment to school and reduce the risk of dropout, and thereby reduce levels of HIV risk factors. Intervention participants received school uniforms, school fees, sanitary pads and underpants, as well as monitoring and assistance from a community visitor. All households in the intervention and comparison groups received twice-monthly food supplements and mosquito nets and blankets.

Promise Place was a school-based case management intervention to prevent repeat teenage pregnancy. Family Advocates met with intervention participants to identify and help set family, personal and graduation goals, and to help prioritize needs and identify resources. Advocates spent at least two hours/month with students, including counseling and (for those on maternity leave or with failing attendance) home visits. When a student graduated, dropped out or returned to their school, they were considered to be in aftercare, which helped students obtain community resources and promoted continuity of care.
-Randomized controlled trial - Unit of randomization: School -Baseline sample: Intervention and comparison groups had a total of 19,289 students; each group had 82 schools

-Follow-up: 3, 5 and 7 years

postintervention

-Attrition: 4\% (both sexes) at 3 years; $15 \%$ of females and $9 \%$

of males at 5 years; and $40 \%$ of females and $33 \%$ of males at 7 years

-Randomized controlled trial - Unit of randomization: Households in close proximity -Baseline sample: Intervention group had 53 youth; comparison group had 52 youth

-Follow-up: 12 and 24 months postbaseline

-Attrition: $2 \%$ in both groups at 12 months, and $2 \%$ in intervention group and $6 \%$ in comparison group at 24 months
Mean age: 13

-Gender: 49\% female, 51\% male

Race/ethnicity: Not stated
-Socioeconomic status: Not stated

Outcomes reported by par-

ticipants, teachers and peers

(percentage-point differences

between intervention and com-

parison groups):

$\mathbf{3}$ years postintervention

-Ever pregnant/caused a pregnancy:

Females: $-2.7\left(\mathrm{SE}_{1} 1.1\right)^{*}$

Males: -0.2 (SE, 0.3$)$

5 years postintervention

-Ever pregnant/caused a pregnancy:

Females: $-4.4(\mathrm{SE}, 1.7)^{* *}$

Males: 0.5 (SE, 0.5)

7 years postintervention

- Condom use at last sex

Females: 1.7 (SE, 2.1)

-Age of oldest partner ever:

Females: -26.9 (SE, 22.6)

-Ever pregnant/caused a pregnancy:

Females: -3.2 (SE, 2.1)

Males: $-0.2\left(\mathrm{SE}_{1}, 8\right)$

Biomarkers (percentage-point dif-

ferences between intervention and comparison groups):

7 years postintervention

- Tested positive for HIV:

Females: $0.4(\mathrm{SE}, 0.6)$

Males: 0.1 (SE, 0.2)

-Tested positive for HSV-2:

Females: 0.9 (SE, 1.4)

Males: 0.5 (SE, 0.9)

Age: 12-14 (mean, 12.9)

12 months postbaseline

Ever had sexual intercourse: GEE, -1.5

-Race/ethnicity: 100\% Lu

-Socioeconomic status: Not stated 24 months postbaseline Ever had sexual intercourse: GEE, -0.1
-Quasi-experimental study - Unit of study: School -Baseline sample: Intervention group consisted of 64 pregnant and 76 parenting students at 1 school; comparison group consisted of 47 pregnant and 16 parenting students at 1 school

-Follow-up: 24 months

postbaseline

-Attrition: $44 \%$ in intervention

group and $46 \%$ in control group
-Age: 13 or older; $>70 \%$ in each group were aged 16-18 -Gender: $100 \%$ female -Race/ethnicity: 46\% Hispanic $34 \%$ black, $8 \%$ white, $12 \%$ other in intervention group; 70\% Hispanic, $13 \%$ black, $8 \%$ white, $10 \%$ other in comparison group

-Socioeconomic status: $64-65 \%$ of students were enrolled in Medicaid
24 months postbaseline -Proportion not pregnant, among those pregnant at baseline: Control: 0.66 (0.41-0.82) Intervention: $0.90(0.72-0.97)$ Risk difference: $\mathrm{p}=0.002$ -Proportion not pregnant, among those parenting at baseline: Control: 1.00 (Cl not reported) Intervention: $0.93(0.79-0.98)$ Risk difference: $\mathrm{ns}$

Table continues 
TABLE 1 (continued)

Intervention

Intervention description

Study design and sample

Participant characteristics

Outcomes

South Africa Cash

Transfer Program,

South Africa ${ }^{64}$

Zimbabwe Schoo Support Program,

Zimbabwe $^{57}$
This conditional cash transfer program was designed to reduce HIV incidence among young women by increasing school enrollment. Each month, intervention participants received 100 Rands ( $R$ ), and their parent/guardian received

R200, if the student attended school on at least $80 \%$ of school days in that month, for up to three years. The funds were deposited directly into separate bank accounts for the young woman and for the parent/guardian.
-Randomized controlled trial - Unit of randomization: Individual -Baseline sample: Intervention group had 1,225 youth; comparison group had 1,223 youth -Follow-up: 12 months (survey) and 36 months (STD testing) postbaseline -Attrition at final follow-up: $5 \%$ in intervention group and 13\% in comparison group
Based on the social development model, this intervention provided support to keep orphan girls in school to reduce their HIV risk. Mechanisms of support included payment of school fees and provision of exercise books, uniforms and other supplies (e.g., soap, sanitary napkins); helpers (female teachers) were trained to monitor participants' attendance and to assist with absenteeism problems, but were not to provide special HIV or life-skills training. When girls started high school, new helpers were selected and trained for those schools.

-Age: grades 8-11 (range, 20-28\% 12 months postbaseline per grade)

-Gender: $100 \%$ female

-Race/ethnicity: Not stated Had pregnancy in past 12 months: Relative risk, $0.9(0.8-1.2)$

-Sexual debut:

students had food insecurity

Sex person-year, 0.9

(0.8-1.1)

- Had unprotected sex in past 3 months:

Relative risk, $0.8(0.7-1.0)^{*}$ -Had any partner in past 12 months: Relative risk, $0.9(0.8-1.0)^{*}$ -Had multiple partners in past 12 months:

Relative risk, 0.9 (0.7-1.1)

-Had partner aged $\geq 25$

Relative risk, 0.9 (0.6-1.1)

-Partner age difference $\geq 5$ years:

Relative risk, 0.9 (0.7-1.1)

$\mathbf{3 6}$ months postbaseline

- Tested positive for HIV:

Hazard ratio, 1.2 (0.9-1.7)

- Tested positive for HSV-2:

Hazard ratio, 0.9 (0.7-1.2)

Randomized controlled trial - Unit of randomization: Schoo -Baseline sample: Intervention group had 184 students at 13 schools; comparison group had 145 students at 12 schools •Follow-up: 12 and 24 months postbaseline

-Attrition: 3\% in intervention group and $4 \%$ in comparison group at 12 months, and $7 \%$ in intervention group and $18 \%$ in comparison group at 24 months
-Mean age: 12

-Gender: $100 \%$ female

-Race/ethnicity: Not stated - Socioeconomic status: Mean no. of $\mathbf{2 4}$ months postbaseline

assets in home was 3.2-3.3 in each .Ever had sexual intercourse: group (scale, 0-12)
12 months postbaseline - Ever had sexual intercourse: $\mathrm{GEE},-0.3$ -Pregnancy status (as reported by teachers/peers): Not reported 


\section{TABLE 1 (continued)}

Intervention

Intervention description

Study design and sample

Participant characteristics

Outcomes

Zomba Cash Transfer Theorized to reduce levels of Program, Malawi ${ }^{50,51}$ economic risk factors for HIV and increase school enrollment, this program provided monthly cash transfers to participants and their guardians to reduce risk of STIs. Cash transfers were provided either unconditionally or on the condition that the participant had attended school at least $75-80 \%$ of the time during the previous month. Cash was split between guardian and participant; the amount varied randomly by enumeration area and by individual. School fees were paid directly to the school for recipients eligible to attend secondary school. The program targeted two groups of young women: those enrolled in school at baseline (baseline schoolgirls) and those who were out of school at baseline (baseline dropouts).
- Randomized controlled trial

- Unit of randomization: Enumera-

tion area

-Baseline sample: Intervention group had 727 participants from 88 enumeration areas; comparison group had 1,050 participants from 88 enumeration areas

-Follow-up: 12 months (survey) and 18 months (STI testing) postbaseline -Attrition: At 12 months, 7-10\% in the intervention group (depending on baseline school attendance status), but not reported for the comparison group; at 24 months, $4 \%$ overall
-Age: 12-22 (mean, 15.6)

-Gender: $100 \%$ female

-Race/ethnicity: Not stated

-Socioeconomic status: Not stated

\section{2 months postbaseline}

-Sexual debut:

Among schoolgirls at baseline:

Odds ratio, 0.7 (0.4-1.1)

Among dropouts at baseline:

Odds ratio, 0.7 (0.3-1.5)

-Condom use with at least one

partner:

Among schoolgirls at baseline:

Odds ratio, 1.1 (0.7-1.8)

Among dropouts at baseline:

Odds ratio, 0.7 (0.4-1.2)

-Had sex once per week

Among schoolgirls at baseline: Odds ratio, $0.5(0.3-0.8)^{* * * *}$

Among dropouts at baseline:

Odds ratio, $0.5(0.3-0.9)^{* * *}$

- Had partner older than 25 .

Among schoolgirls at baseline:

Odds ratio, $0.2(0.1-0.6)^{* * *}$

Among dropouts at baseline:

Odds ratio, 0.8 (0.4-1.5)

-Currently pregnant

Among schoolgirls at baseline:

Odds ratio, 0.7 (0.4-1.4)

Among dropouts at baseline:

Odds ratio, $0.6(0.3-1.1)$

18 months postbaseline

- Tested positive for HIV:

Among schoolgirls at baseline:

Odds ratio, 0.4 (0.1-0.9)*

Among dropouts at baseline:

Odds ratio, 1.4 (0.7-2.6)

-Tested positive for HSV-2:

Among schoolgirls at baseline:

Odds ratio, 0.2 (0.1-0.7)**

Among dropouts at baseline:

Odds ratio, $1.0(0.5-2.2)$

-Tested positive for syphilis:

Among schoolgirls at baseline:

Odds ratio, 0.9 (0.1-6.9)

Among dropouts at baseline:

Odds ratio, $1.6(0.3-10.0)$

${ }^{*} \mathrm{p} \leq .05 .{ }^{* *} \mathrm{p}<.01 .{ }^{* * *} \mathrm{p}<.001 . \mathrm{tp}<.10$. Notes: Unless otherwise noted, all odds ratios, effect sizes and similar results represent outcomes in the intervention group relative to the comparison group, "sex" refers to vaginal intercourse and outcomes were self-reported. An outcome is described as "not reported" if the measure was listed as an outcome in the article but no results were reported; such instances are noted here because of their relevance to assessment of risk of bias. Percentages may not total $100 \%$ because of rounding. GEE $=$ generalized estimating equation. $\mathrm{ns}=$ not significant. $\mathrm{SE}=$ standard error. $\mathrm{Cl}=$ confidence interval. 
TABLE 2. Risk of bias in studies included in systemic review, by domain

\begin{tabular}{|c|c|c|c|c|c|c|c|}
\hline Intervention & $\begin{array}{l}\text { Random generation of } \\
\text { allocation sequence }\end{array}$ & $\begin{array}{l}\text { Allocation } \\
\text { concealment }\end{array}$ & Blinding & $\begin{array}{l}\text { Complete } \\
\text { outcome data }\end{array}$ & $\begin{array}{l}\text { Selective outcome } \\
\text { reporting }\end{array}$ & $\begin{array}{l}\text { Accounted for } \\
\text { clustering }\end{array}$ & $\begin{array}{l}\text { Other sources } \\
\text { of bias }\end{array}$ \\
\hline Aban Aya Youth Project ${ }^{55}$ & Unclear & Unclear & Unclear & Unclear & Unclear & Low & Low \\
\hline Gatehouse Project ${ }^{63}$ & Unclear & Unclear & Unclear & Unclear & Unclear & Low & High \\
\hline Kenya Education Subsidy Program ${ }^{54}$ & Low & Unclear & Unclear & High & Unclear & Low & Low \\
\hline Kenya School Support Program ${ }^{53,56}$ & Low & Unclear & Unclear & Low & Unclear & Unclear & Low \\
\hline Positive Action ${ }^{52,65}$ & Unclear & Unclear & Unclear & Unclear & Unclear & Low & High \\
\hline PREPARE $^{62}$ & Low & Low & High & Unclear & Unclear & Low & Low \\
\hline Promise Place Program ${ }^{66}$ & na & na & Unclear & High & Unclear & High & Low \\
\hline Seattle Social Development Project ${ }^{58-61}$ & na & na & Unclear & Unclear & Unclear & Low & High \\
\hline South Africa Cash Transfer Program ${ }^{64}$ & Unclear & Low & Unclear & Unclear & High & na & Low \\
\hline Zimbabwe School Support Program ${ }^{57}$ & Unclear & Unclear & Unclear & Unclear & Unclear & Low & Low \\
\hline Zomba Cash Transfer Program ${ }^{50,51}$ & Low & Unclear & Unclear & Low & High & Low & High \\
\hline
\end{tabular}

na=not applicable (because study was quasi-experimental or because unit of randomization was individuals rather than groups). 